\title{
Neuroanatomical correlates of food addiction and obesity in the general population
}

Beyer, F.*: Department of Neurology, Max Planck Institute for Human Cognitive and Brain Sciences, Leipzig.

García-García, I.*: Montreal Neurological Institute, McGill University, Montreal

Heinrich, M.: EGG-Lab, Department of Neurology, Max Planck Institute for Human Cognitive and Brain Sciences, Leipzig.

Scholz, M., Institute for Medical Informatics, Statistics and Epidemiology, University of Leipzig, Leipzig.

Schroeter, ML, Department of Cognitive Neurology, University Hospital, Leipzig; Department of Neurology, Max Planck Institute for Human Cognitive and Brain Sciences, Leipzig

Sacher, J.: EGG-Lab, Max Planck Institute for Human Cognitive and Brain Sciences, Leipzig

Luck, T.: Institute of Social Medicine, Occupational Health and Public Health (ISAP)

Riedel-Heller, S.G.: Institute of Social Medicine, Occupational Health and Public Health (ISAP)

Stumvoll, M.: Clinic for Endocrinology and Nephrology, University Hospital, Leipzig

Villringer, A.: Department of Neurology, Max Planck Institute for Human Cognitive and Brain Sciences, Leipzig; Department of Cognitive Neurology, University Hospital, Leipzig

Witte, A.V.: Department of Neurology, Max Planck Institute for Human Cognitive and Brain Sciences, Leipzig.

* Shared first authorship

Corresponding author:

Witte, A.V.: Department of Neurology, Max Planck Institute for Human Cognitive and Brain Sciences, Stephanstr. 1a, 04103 Leipzig, phone: 004934199402426, email: witte@cbs.mpg.de

short title: Neuroanatomical correlates of food addiction 
Acknowledgments: We would like to thank all participants and staff of the LIFE-Adult study, as well as Anja Dietrich for helpful discussions. This work was supported by grants of the European Union, the European Regional Development Fund, the Free State of Saxony within the framework of the excellence initiative, the LIFE-Leipzig Research Center for Civilization Diseases, University of Leipzig [project numbers: 713-241202, 14505/2470, 14575/2470] and by grants of the German Research Foundation, contract grant number CRC 1052 "Obesity mechanisms" Project A1, A. Villringer/M. Stumvoll, SCHR 774/5-1, M. L. Schroeter, and WI 3342/3-1, A.V. Witte, and by a Branco Weiss Fellowship, Society in Science to J. Sacher, and by a NARSAD Young Investigator Award by the Brain \& Behavior Research Foundation to J. Sacher, and by the Max Planck Society. 


\section{Abstract}

The food addiction model suggests neurobiological similarities between substance-related and addictive disorders and obesity. While structural brain differences have been consistently reported in these conditions, little is known about the neuroanatomical correlates of food addiction. We therefore assessed whether food addiction, assessed with the Yale Food Addiction Scale (YFAS), related to obesity, personality and brain structure in a large population-based sample $(n=625 ; 20$ 59 years old, $45 \%$ women). A higher YFAS symptom score correlated with obesity and disinhibited eating. In a whole-brain analysis, YFAS symptom score was not associated with cortical thickness nor subcortical gray matter volumes. Higher body mass index (BMI) correlated with reduced thickness of (pre)frontal, temporal and occipital cortex. Bayes factor analysis suggested that BMI and - to a smaller extent - YFAS symptom score contributed independently to right lateral orbitofrontal cortex thickness. Our study shows that food addiction is not associated with neuroanatomical differences in a large population-based sample, and does not account for the major part of obesity-associated gray matter alterations. Yet, food addiction might explain additional variance in orbitofrontal cortex, a hub area of the reward network. Longitudinal studies implementing both anatomical and functional MRI could further disentangle the neural mechanisms of addictive eating behaviors.

Key words (7): Food addiction, Obesity, Body Mass Index, Gray Matter, Neuroimaging, Eating, Cohort Studies 


\section{Main text}

The food addiction model provides a theoretical framework that explains the development of obesity based on observed similarities between substance addictions and overeating behavior (Randolph, 1956; Gearhardt et al., 2009). Essentially, this model proposes that some individuals exhibit eating patterns, elicited by certain types of food, that resemble addictive behaviors with regard to loss of control over eating and continued food consumption despite harmful consequences (Volkow et al., 2013b; Volkow et al., 2013a; Hebebrand et al., 2014; Schulte et al., 2015) but see (Ziauddeen et al., 2012).

Evidence in support of this hypothesis has been found in patients with eating disorders (Gearhardt et al., 2014) but also in epidemiological cohorts (Pedram et al., 2013; Flint et al., 2014; Pursey et al., 2016) where self-reported food addiction correlated with higher body mass index (BMI) and other measures of obesity.

Previous neuroimaging studies have highlighted the putative role of the prefrontal cortex and dopamine-dependent fronto-striatal circuits in dysfunctional self-regulation which could underlie both substance-related and addictive disorders and pathological eating behavior (Fineberg et al., 2010; García- García et al., 2014; Voon et al., 2015; García-García et al., 2017). For example, positron emission tomography studies reported lower dopamine D2/D3 striatal receptor binding both in participants with substance-related and addictive disorders (Volkow et al., 2008) and in morbidly obese individuals (Wang et al., 2001). Along these lines, participants with food addiction showed altered reward-related brain activity in the dorsolateral and orbitofrontal cortex and in the caudate nucleus in response to anticipated receipt of (rewarding) food (Gearhardt et al., 2011).

Regarding structural variation in addictive disorders, several studies reported lower grey matter volume (GMV) in the inferior and superior frontal cortex, orbitofrontal cortex and medial occipital 
gyrus that discriminated stimulant-dependent individuals from non-dependent controls (Durazzo et al., 2011; Fortier et al., 2011; Ersche et al., 2012; Moreno-López et al., 2012; Pennington et al., 2015). Lower GMV in middle and orbitofrontal areas also had a prognostic value in predicting alcohol dependence relapse after 12 months (Durazzo et al., 2011).

Similarly, obesity has been consistently associated with reduced GMV and lower cortical thickness in (pre)frontal cortex, the temporal lobe and bilateral cerebellum (Hassenstab et al., 2012; Marqués-Iturria et al., 2013; Kharabian Masouleh et al., 2016; García-García et al., 2018).

Several studies in middle- to aged populations raised the hypothesis that the observed gray matter volume loss is mainly a consequence of adverse metabolic factors related to obesity (Gustafson et al., 2004; Janowitz et al., 2015; Willette and Kapogiannis, 2015; Shahrzad Kharabian et al., 2017). Low-grade inflammation and dysregulated glucose metabolism, for example, may trigger damage to nervous tissue and contribute to accelerated brain aging and the increased risk for dementia associated with obesity (Beydoun et al., 2008; Baumgart et al., 2015; Ronan et al., 2016). Another line of research suggests that altered gray matter structure in brain regions that govern aspects of eating behavior may represent a risk factor for weight gain and obesity (Yokum et al., 2011; Hassenstab et al., 2012; Smucny et al., 2012; Opel et al., 2017).

Taken together, according to the food addiction model, addictive-like eating behavior is one of multiple factors that contribute to obesity. Akin neurobiological mechanisms might underlie both substance-related and addictive disorders and obesity (Volkow et al., 2008; Volkow et al., 2013b; García- García et al., 2014) and possibly account for impulsive and compulsive behaviors in these disorders (Michaud et al., 2017). Both addictive disorder and obesity are associated with alterations in gray matter structure, however, structural variation related to food addiction remains largely unexplored. 
Here, we aimed to determine the relation of food addiction with obesity and brain morphology in a large population-based cohort. We hypothesized that food addiction was associated with structural alterations in fronto-striatal brain areas. To investigate the role of food addiction within the multiple factors involved in obesity (Hruby and Hu, 2015), we tested whether food addiction predicted different measures of obesity, including abdominal MRI-based body fat, as well as measures of eating behavior and general personality features (Vainik et al., 2013; Gerlach et al., 2014). We additionally assessed obesity-related differences in brain structure and compared the evidence for the involvement of BMI and food addiction in selected regions of interest using a Bayesian statistical approach.

\section{Methods}

\section{Participants}

All participants were enrolled in the "Health Study for the Leipzig Research Centre for Civilization Diseases" (LIFE-Adult) study (Loeffler et al., 2015). We selected adult participants from the neuroimaging cohort $(\mathrm{n}=2637)$ with available head MRI and without history of neurological or psychiatric disease such as stroke, cancer, epilepsy, multiple sclerosis and Parkinson's disease. We restricted the age range to younger and middle-aged participants (20 to 59 years old) to avoid overestimation of aging-related effects in the brain among participants older than 60 years (Fjell et al., 2012; Storsve et al., 2014). Included participants did not take central nervous system agents and had complete data for the primary covariates Yale Food Addiction Scale (YFAS) and body mass index (BMI). Due to potential links between food addiction and depression (Davis et al., 2011), participants were excluded if they reported major depressive disorder in the last 12 months or scored > 21 in the CES-D (Center for Epidemiological Studies-Depression) (Radloff, 1977). In total, 625 participants met inclusion criteria, and were included into the main analysis (Figure 1). 
Out of these, $n=444$ underwent abdominal MRI and $n>423$ completed further questionnaires assessing eating behavior and personality.

Figure 1 here

\section{Food addiction questionnaire}

We measured food addiction using the Yale Food Addiction scale (YFAS) (Gearhardt et al., 2009). This questionnaire applied the DSM-IV criteria for substance dependence to eating behavior. The items of the scale have shown good internal consistency (Meule et al., 2012). We selected the continuous food addiction symptom score ranging from 0 to 7 as the primary variable of interest in our analyses as only $6 \%$ of the population meet criteria for manifest food addiction (Flint et al., 2014), and food addiction, like other psychopathological traits, might be better represented in a continuum (Kozak and Cuthbert, 2016).

\section{Head Magnetic Resonance Imaging}

Anatomical T1 images were acquired using a 3 Tesla Siemens Verio MRI scanner (Siemens Healthcare, Erlangen, Germany) with a 3D MPRAGE protocol with the following parameters: inversion time, 900 ms; repetition time, 2300 ms; echo time, 2.98 ms; flip angle, 9o; field of view, $256 \times 240 \times 176 \mathrm{~mm}^{3}$; voxel size, $1 \times 1 \times 1 \mathrm{~mm}^{3}$.

Cortical thickness was estimated using Freesurfer's standard pipeline recon-all (version 5.3.0) (Dale et al., 1999). Cortical thickness data was smoothed with a Gaussian kernel of $10 \mathrm{~mm}$ fullwidth at half maximum on the fsaverage template (Fischl and Dale, 2000). All images were visually checked for misplaced tissue boundaries and 56 images ( 10\%) were manually corrected. Three participants had to be excluded due to motion-related scan artifacts and segmentation errors. 
Subcortical volumes were obtained from automated labeling (Fischl et al., 2002). Previous studies have emphasized the importance of the fronto-striatal circuits in addictive-like behaviors (Tomasi and Volkow, 2013; García- García et al., 2014; García-García et al., 2017). We therefore included the following structures: thalamus, caudate, putamen, pallidum, accumbens, and amygdala. For each subcortical structure, we extracted the volume for the right and left hemispheres separately and divided it by the total intracranial volume to account for head size. Two participants were identified as outliers in the subcortical analysis and were excluded due to enlarged ventricles and subcortical hyperintensities.

\section{Obesity-related variables}

We used 4 anthropometric measures to characterize obesity (Pou et al., 2007; Amato et al., 2013): (i) body mass index (BMI), (ii) waist-to-hip ratio (WHR), (iii) subcutaneous adipose tissue divided by height (SCAT), and (iv) visceral adipose tissue divided by height (VAT).

BMI was used as a main measure to reflect obesity, since it is widely reported in studies in the field. WHR was recorded since it is considered to reflect visceral fat deposition (Lee et al., 2008). In addition, a subgroup of participants $(n=444)$ underwent an abdominal T1-weighted MRI scan (Raschpichler et al., 2013). This acquisition covered the abdominal region starting $10 \mathrm{~cm}$ proximal and ending $10 \mathrm{~cm}$ distal from the umbilicus with a layer thickness of $1 \mathrm{~cm}$. Sequence parameters can be found in the appendix. The subcutaneous and the visceral adipose tissues were quantified by means of semi-automated image segmentations (Raschpichler et al., 2013) and normalized by height (Vanltallie et al., 1990). 


\section{Eating behavior and personality questionnaires}

We additionally characterized eating behavior by means of the Three Factor Eating Questionnaire (TFEQ) (Stunkard and Messick, 1985; Löffler et al., 2015b; Löffler et al., 2015a) which provides 3 measures of human eating behavior: (i) cognitive restraint of eating, (ii) disinhibited eating, and (iii) hunger. General personality traits were assessed with the short version of the NEO-FFI questionnaire, which provides measures for neuroticism, extraversion, openness, agreeableness, and conscientiousness (Körner et al., 2008).

Chronic stress was assessed with the screening scale of chronic stress (SSCS) from the Trierer Inventar zum Chronischen Stress (TICS) (Schulz et al., 2004). CES-D (Center for Epidemiological Studies-Depression) scores were used for exclusion (CES-D > 21) and to control for subthreshold depressive symptoms (Radloff, 1977; Klinkman, 1997).

\section{Statistical analysis}

For all statistical analyses, we used log-transformed values of the YFAS symptom score and the obesity-related variables (except WHR) to ensure normal distribution of regression residuals.

\section{Linear regression analysis of food addiction, obesity and personality measures}

We used multiple regressions to explore associations between YFAS symptom score and the variables of interest (i) measures of obesity (ii) eating-behavior and personality, controlling for age, sex (with males as reference category) and BMI. Analyses were performed in R version 3.2.3. 


\section{Cortical thickness analysis}

We applied whole-brain vertex-wise analyses of cortical thickness and YFAS symptom score using Freesurfer's mri_glmfit. In Model 1, we included YFAS symptom score, age and sex, in Model 2, we included BMI, age and sex and in Model 3 we included YFAS symptom score, BMI, age and sex.

Clusterwise correction for multiple comparisons based on pre-computed Monte-Carlo simulation was performed (cluster-forming threshold $p=0.0001$, familywise error (FWE) corrected $p<0.05$ ). We applied the same statistical models in $\mathrm{R}$ (version 3.2.3) to analyze differences in subcortical volumes. Here, we accounted for multiple testing using Bonferroni's correction $\left(\alpha_{B F}=0.05 / 12=\right.$ 0.004 ) for the 12 regions of interest ( 6 per hemisphere).

\section{Region of interest analysis using Bayes factor}

Extending the whole-brain analysis, we aimed to weight the evidence for a contribution of food addiction, BMI or a combination of both to structural differences in selected regions of interest using Bayes factors.

Bayes factors (BF) quantify how likely the data are to occur under the assumption of one model compared to another (Goodman, 1999). More precisely, the Bayes factor $\mathrm{BF}_{12}$ is calculated as the ratio of the likelihood of the data given model 1 over the likelihood of the data given model 2. According to (Kass and Raftery, 1995), a $\mathrm{BF}_{12}$ between 3 and 20 indicates positive evidence for model 1 over model 2, a $\mathrm{BF}_{12}$ between 20 and 150 indicates strong, and a $\mathrm{BF}>150$ indicates very strong evidence for model 1 over model 2.

Here, we first compared Model 1 (including age, sex and YFAS symptom score) and Model 2 (including age, sex and BMI) to a null model including only age and sex. If this comparison yielded positive evidence for either BMI or YFAS symptom score (defined as a Bayes Factor > 3, (Kass and Raftery, 1995)), we additionally compared the models including YFAS symptom score and BMI alone (adjusted for age and sex, Model 1 vs Model 2), and the model including BMI along 
with YFAS symptom score to the model including BMI alone (adjusted for age and sex, Model 3 vs Model 2). To assess the collinearity of age, BMI and YFAS symptom score, we calculated the variance inflation factor (VIF) with the package "car" 2.1-3 in R.

We selected (orbito)frontal cortex and nucleus accumbens as ROls, as structural differences in these regions were previously related to food addiction (Maayan et al., 2011) and obesity (Rapuano et al., 2017; García-García et al., 2018). We extracted individual cortical thickness values based on the Desikan-Killiany parcellation in Freesurfer for lateral OFC and medial OFC, rostral and superior frontal cortex on both hemispheres.

We used the package 'BayesFactor' version 0.9.12 in $\mathrm{R}$ version 3.2.3 to calculate and compare Bayes factors.

\section{RESULTS}

\section{Sample characteristics}

Table 1 here

The items of the food addiction scale showed an acceptable internal consistency in the current sample of 625 healthy adults (Cronbach's $\alpha=0.78$ ). YFAS symptom score was not significantly associated with age, sex or depression scores (all p > 0.05) (see Figure 2). 56 participants (8.9\%) showed three or more symptoms of food addiction. Among those, eight participants (1.3\%) fulfilled the diagnosis criteria for food addiction and additionally reported clinical impairment or distress (Meule et al., 2012).

Figure 2 here 


\section{Association of food addiction and obesity-related measurements}

YFAS symptom score predicted BMI and WHR in the multiple regression analyses independent of age and sex. In the subgroup of participants with MRI-based measures of abdominal fat $(\mathrm{n}=$ 444), we also found that YFAS symptom score was positively associated with SCAT but not VAT (Figure 3; Table 2).

Figure 3 here

Table 2 here

Figure 4 here

\section{Relationship between food addiction, eating behavior and personality}

In the multiple regression analyses, YFAS symptom scores explained variance in disinhibited eating (TFEQ), hunger (TFEQ), neuroticism (NEO-FFI) and chronic stress (TICS) after accounting for the effect of age, sex and BMI. In the four analyses, the directionality of the relation was positive (Figure 4; Table 3).

Table 3 here

\section{Food addiction, obesity and cortical thickness}

There was no statistically significant association of YFAS symptom score and cortical thickness with Model 1 (adjusting for age and sex) or Model 3 (additionally adjusting for BMI) (whole-brain FWE-corrected all $\left.p_{\text {cluster }}>0.05\right)$.

Model 2 reveiled significant associations of BMI and cortical thickness adjusting for age and sex. Higher BMI was associated with cortical thinning in right lateral orbitofrontal cortex (OFC), rostral middle frontal, parahippocampal, isthmus cingulate and left lateral occipital cortex and middle and superior temporal cortex (see Table 4, Figure 5). When adjusting for YFAS symptom 
score (Model 3), all clusters except for the cluster in the isthmus cingulate remained significantly associated with BMI (Table 4; data not shown).

Figure 5 here

Table 4 here

\section{Food addiction, obesity and subcortical gray matter volumes}

No significant correlations between YFAS scores and the subcortical volumes of interest emerged after age, sex (Model 1) and age,sex and BMl correction (Model 3) (all p > 0.004). BMl was significantly positively associated with increased left accumbens volume after correction for multiple comparisons (Model 2: standardized $\beta=0.15, p<0.001$, Model 3: standardized $\beta=0.14$, $\mathrm{p}=0.002$ ). (for detailed results see supplementary table $\mathrm{S} 1$ ).

\section{Bayes model comparison}

For the predefined regions of interest (right and left medial and lateral OFC, superior frontal and rostral middle frontal cortex, nucleus accumbens), we compared the evidence for models including age, sex and a) BMI b) YFAS symptom score and c) BMI and YFAS symptom score using Bayes factors (see Table 5).

The variance inflation factors of age, BMI and YFAS were 1.22, 1.29 and 1.03, respectively.

For the right medial OFC, the analysis provided evidence in favor of a model including BMI, age and sex compared to a model including only age and sex $(B F=266)$ or a model including YFAS symptom score, age and sex (BF=52). The data equally supported the model including BMI, YFAS symptom score, age and sex $(B F=0.86)$.

In case of the right lateral OFC, there was very strong evidence for a model including BMI, age and sex (BF=1997). Strong evidence suggested a model including YFAS, age and sex (BF=107), 
however when comparing the age and sex-adjusted models with BMI and YFAS, the BMI model was preferred $(B F=18)$. Positive evidence suggested including both YFAS and BMI $(B F=11)$.

For right superior frontal, rostral middle frontal cortex and nucleus accumbens, the null hypothesis was preferred over age and sex-adjusted models including BMI or YFAS symptom score (all BF of comparison against null $<1 / 3)$.

Regarding the left hemisphere, no positive evidence for an association of BMI or YFAS symptom score and OFC or frontal cortical thickness was found (all BF of comparisons against null $<1 / 3$ ). In line with the linear regression, a Bayes factor of 48 suggested strong evidence for an association of BMI and nucleus accumbens volume. Including both BMI and YFAS yielded a model that was equally likely $(\mathrm{BF}=1.16)$, and including an age-and sex-adjusted model with BMI was favored over a model including YFAS symptom score (BF=28).

Table 5 here

\section{DISCUSSION}

YFAS symptom score explained inter-individual variance in obesity measures, uncontrolled eating behavior and negative emotionality in a population-based cohort of 625 participants. In a whole brain approach, YFAS symptom score was not significantly associated with cortical thickness. In contrast, higher BMI was independently associated with reduced cortical thickness in right prefrontal, orbitofrontal and parahippocampal cortex and left temporal and occipital cortex. In addition, Bayes factor ROI analyses suggested a small contribution of YFAS symptom score to the cortical thickness of right lateral OFC, in addition to BMI. 


\section{Neural correlates of food addiction and obesity}

In this well-powered analysis (Pardoe et al., 2013), we found no statistically significant association of YFAS symptom score and cortical thickness on a whole-brain level. Similarly, subcortical volumes were not associated with YFAS symptom score. Regarding obesity, our analysis largely confirmed previous findings of BMI-associated reduced gray matter volume/cortical thickness. We replicated consistently reported lower gray matter volume in the right medial prefrontal cortex related to obesity, more specifically in its rostral subdivision and the orbitofrontal cortex (GarcíaGarcía et al., 2018). BMl was also associated with reduced cortical thickness in right parahippocampal, left temporal and lateral occipital regions and increased left accumbens volume (Veit et al., 2014; Walhovd et al., 2014; Rapuano et al., 2017). As we used Freesurfer cortical and subcortical analysis, we did not assess the previously reported relation of BMI and cerebellar gray matter volume (Kharabian Masouleh et al., 2016; García-García et al., 2018).

All findings related to BMI remained essentially unaltered after adjusting for YFAS symptom score.

These findings indicate that addictive-like eating behavior does not account for the major part of structural differences related to obesity in the general population.

Accordingly, the model comparison using Bayes factors indicated that BMI rather than YFAS symptom score explained cortical thinning in frontal regions of the right hemisphere, and increased volume of the left nucleus accumbens. For the right lateral OFC, the data however also supported a model including YFAS symptom score alone, though this was 20 times less likely. Yet, positive evidence indicated that both BMI and YFAS symptom score might be associated with cortical thinning in this region. These - compared to the whole-brain analysis - somewhat conflicting findings should be interpreted cautiously. On the one hand, the evidence based on Bayes factors in the ROI analysis is moderate, making a definite conclusion about the association of YFAS and OFC cortical thickness difficult. On the other hand, in whole-brain, family-wise error corrected analyses, the larger effect size of BMI score and other factors such as age and sex 
compared to YFAS symptom, as well as the collinearity of BMI and YFAS symptom score, might have masked the small effect of food addiction. The OFC is a cardinal structure in our understanding of impulsive- and/or compulsive-related behavior (Zeeb et al., 2010; Burguière et al., 2013). Structural alterations in the OFC have been associated with impaired ability for goaldirected behavior (Reber et al., 2017) and impulsivity (Matsuo et al., 2009) and several studies reported diminished cortical thickness or GMV in the OFC of individuals with substance-related disorders (Durazzo et al., 2011; Ersche et al., 2012; Chye et al., 2017). More specific to overeating behaviors, reduced OFC gray matter volume and thickness have been related to less restrained eating (Su et al., 2017) and unhealthy food choice (Cohen et al., 2011), although one study reported larger OFC volume in binge-eating disorder patients compared to healthy controls (Schäfer et al., 2010). Structural alterations in OFC thickness could provoke, or fail to inhibit, impulsive and compulsive eating behavior, which would be partially captured by the YFAS symptom score.

Meanwhile, we find strong evidence for an association of BMI and lower cortical thickness in the OFC which might result from the adverse metabolic consequences of obesity (Cazettes et al., 2011; Dingess et al., 2017), and thus not be causally related to food addiction (Marqués-Iturria et al., 2013; Kharabian Masouleh et al., 2016; Thompson et al., 2017). Obesity, and especially visceral fat accumulation, is known to coincide with adverse metabolic responses, such as increased low-grade inflammation or progressive insulin resistance (Van Gaal et al., 2006), that enhance the vulnerability of the brain tissue (Corlier et al., 2018). Therefore, even though an association of reduced OFC thickness and addictive-like eating behavior seems plausible and is somewhat supported by the data, the current cross-sectional study provides evidence for a negative association of obesity and (orbito)frontal cortex thickness, largely independent of food addiction. Future studies investigating the neurobiological mechanisms underlying food addiction and obesity should therefore be longitudinal, include more sensitive assessments of addictive- 
like or uncontrolled eating behavior (Vainik et al., 2015) and investigate brain function, in addition to structure, related to these eating behaviors, for example using task-based functional MRI (Schag et al., 2013).

\section{Food addiction related to obesity and personality}

Although the percentage of participants with high YFAS symptom score is low in general populations (Pedram et al., 2013), addictive-like behaviors might contribute to the high prevalence of obesity in modern societies (Schulte et al., 2016)(Hauck et al., 2017). A previous study, for instance, reported that participants tend to experience food addiction symptoms in relation to highfat and sweet or savory foods (Markus et al., 2017). This result suggests that homeostatic mechanisms might be overwritten in favor of hedonic or habit-based eating. Such ingestive behavior might ultimately lead to weight gain. In line with these observations, we obtained modest but consistent positive correlations between food addiction and different measures of obesity. Further, our findings of linear relationships between YFAS symptom scores and obesity measures highlight that "food addiction" per se might rather be regarded as a dimensional trait which, like other psychopathological traits, might not fit traditional 1 versus 0 ("all or none") diagnostic categories (Kozak and Cuthbert, 2016). Our results support a certain collinearity between obesity and food addiction (Pedram et al., 2013; Gearhardt et al., 2014; Pursey et al., 2016). Thus, taking into account individual tendencies for addictive-like eating behaviors might inform clinical approaches targeting trans-diagnostic symptoms of addictive behaviors, such as heightened impulsivity or compulsivity.

In the present study, higher YFAS symptom score was also associated with increased scores in disinhibited eating and hunger, two scales that reflect overeating and subjective food cravings, respectively. It is indeed possible that food addiction, disinhibited eating and hunger are partly overlapping scales, since they all do represent hyperphagia and loss of control over eating. In fact, some authors have suggested that different eating-related questionnaires tend to capture 
individual variations in "uncontrolled eating", a dimension reflecting decreased self-control over eating (Vainik et al., 2015).

We additionally observed that YFAS symptom score was significant predictors of neuroticism, a personality trait linked with increased sensitivity to punishment and for negative emotionality (Costa and McCrae, 1985). This result is in line with previous findings suggesting that increases in depressive symptoms or emotional dysregulation significantly contribute to food addiction (Pivarunas and Conner, 2015; Chao et al., 2017; Markus et al., 2017). Again, the relationship between negative emotionality and food addiction could be reciprocal. A longitudinal study on a large cohort of female adolescents observed that depressive symptoms at baseline predicted the development of overeating behavior, while overeating behavior also predicted the onset of depressive symptoms (Skinner et al., 2012). Note that in the current analyses, we avoided confounding of potential manifest depression by excluding participants with CES-D scores > 21 and the majority of those were females. Notably, we did not observe sex differences in the YFAS symptom score, which might point to a similar prevalence of food addiction symptoms in both

women and men. However, please note that we excluded participants with neurological and psychiatric disorder or symptoms and focused on a healthy cohort. In this rather homogenous sample, presumable sex differences in food addiction, as seen in many psychiatric disorders (Dohrenwend and Dohrenwend, 1976) might have been masked out.

\section{Methodological considerations}

We would like to acknowledge three important limitations of the current study.

First, we assessed addictive-like eating behavior with the YFAS symptom score, which has a limited range $(0-7)$ with relatively little variation in the current population. It might therefore lack sensitivity for inter-individual differences in impulsive-compulsive eating behavior (Vainik et al., 
2015). Second, we collected no measurement for binge eating behavior. Food addiction presents some clinical overlap with binge eating disorder, since both conditions entail loss of control over food consumption along with continued use despite adverse consequences (Vainik et al., 2015; Kessler et al., 2016; Schulte et al., 2016). Third, we cannot conclude on the directionality of the associations due the cross-sectional nature of our study. Strengths of our study include a large, well-characterized population-based sample with high-resolution cranial MRI, several proxies of obesity including highly sensitive MRI-derived estimates of abdominal and subcutaneous fat, extensive questionnaires, and strict controls for possible confounding effects in the statistical analyses.

\section{Conclusions and Outlook}

The present study shows no association of food addiction symptoms and cortical thickness in a whole brain analysis. We confirm previous findings of obesity-related cortical thinning in frontal, temporal and occipital brain regions. ROI-based Bayesian analysis suggests that BMI and YFAS symptom score might be independently negatively associated with right lateral OFC thickness.

Our findings indicate that symptoms of food addiction do not account for the major part of the structural differences commonly associated with obesity. Therefore, one plausible interpretation of our cross-sectional finding is that obesity-associated differences in brain morphology represent consequences of metabolic factors related to obesity, even in young to middle-aged healthy adults. Considering the overall low intensity of addictive-like eating behavior in our cohort, it is likely that subtle functional rather than gross structural differences in frontal areas drive these behaviors. Finally, it is also possible, that a vicious cycle relates structural differences, addictivelike eating behavior and obesity. Structural differences in frontal brain regions, induced by obesity- 
related factors, might further exacerbate impulsive and compulsive aspects of eating behavior, similar as in addictive disorders, and thereby lead to weight gain or reduced dieting success (Stevens et al.; DelParigi et al., 2007; Janssen et al., 2017). Thus, strategies aiming to reduce impulsive and compulsive eating behaviors might be beneficial in the treatment of obesity. 


\section{REFERENCES}

Amato M, Guarnotta V, Giordano C (2013) Body composition assessment for the definition of cardiometabolic risk. J Endocrinol Invest 36:537-543.

Baumgart M, Snyder HM, Carrillo MC, Fazio S, Kim H, Johns H (2015) Summary of the evidence on modifiable risk factors for cognitive decline and dementia: A populationbased perspective. Alzheimers Dement 11:718-726.

Beydoun MA, Beydoun HA, Wang Y (2008) Obesity and central obesity as risk factors for incident dementia and its subtypes: a systematic review and meta-analysis. Obes Rev 9:204-218.

Burguière E, Monteiro P, Feng G, Graybiel AM (2013) Optogenetic stimulation of lateral orbitofronto-striatal pathway suppresses compulsive behaviors. Science 340:1243-1246.

Cazettes F, Cohen JI, Yau PL, Talbot H, Convit A (2011) Obesity-mediated inflammation may damage the brain circuit that regulates food intake. Brain Res 1373:101-109.

Chao AM, Shaw JA, Pearl RL, Alamuddin N, Hopkins CM, Bakizada ZM, Berkowitz RI, Wadden TA (2017) Prevalence and psychosocial correlates of food addiction in persons with obesity seeking weight reduction. Compr Psychiatry 73:97-104.

Chye Y, Solowij N, Suo C, Batalla A, Cousijn J, Goudriaan AE, Martin-Santos R, Whittle S, Lorenzetti V, Yücel M (2017) Orbitofrontal and caudate volumes in cannabis users: a multi-site mega-analysis comparing dependent versus non-dependent users. Psychopharmacology 234:1985-1995.

Cohen JI, Yates KF, Duong M, Convit A (2011) Obesity, orbitofrontal structure and function are associated with food choice: a cross-sectional study. BMJ Open 1.

Corlier F, Hafzalla G, Faskowitz J, Kuller LH, Becker JT, Lopez OL, Thompson PM, Braskie MN (2018) Systemic inflammation as a predictor of brain aging: Contributions of physical activity, metabolic risk, and genetic risk. Neuroimage 172:118-129.

Costa PT, McCrae RR (1985) The NEO personality inventory.

Dale AM, Fischl B, Sereno MI (1999) Cortical surface-based analysis: I. Segmentation and surface reconstruction. Neuroimage 9:179-194.

Davis C, Curtis C, Levitan RD, Carter JC, Kaplan AS, Kennedy JL (2011) Evidence that 'food addiction'is a valid phenotype of obesity. Appetite 57:711-717.

DelParigi A, Chen K, Salbe AD, Hill JO, Wing RR, Reiman EM, Tataranni PA (2007) Successful dieters have increased neural activity in cortical areas involved in the control of behavior. International journal of obesity 31:440.

Dingess PM, Darling RA, Kurt Dolence E, Culver BW, Brown TE (2017) Exposure to a diet high in fat attenuates dendritic spine density in the medial prefrontal cortex. Brain Structure and Function 222:1077-1085.

Dohrenwend BP, Dohrenwend BS (1976) Sex differences and psychiatric disorders. American journal of sociology 81:1447-1454.

Durazzo TC, Tosun D, Buckley S, Gazdzinski S, Mon A, Fryer SL, Meyerhoff DJ (2011) Cortical thickness, surface area, and volume of the brain reward system in alcohol dependence: relationships to relapse and extended abstinence. Alcoholism: Clinical and Experimental Research 35:1187-1200.

Ersche KD, Jones PS, Williams GB, Turton AJ, Robbins TW, Bullmore ET (2012) Abnormal brain structure implicated in stimulant drug addiction. Science 335:601-604.

Fineberg NA, Potenza MN, Chamberlain SR, Berlin HA, Menzies L, Bechara A, Sahakian BJ, Robbins TW, Bullmore ET, Hollander E (2010) Probing compulsive and impulsive behaviors, from animal models to endophenotypes: a narrative review. Neuropsychopharmacology 35:591. 
Fischl B, Dale AM (2000) Measuring the thickness of the human cerebral cortex from magnetic resonance images. Proceedings of the National Academy of Sciences 97:11050-11055.

Fischl B, Salat DH, Busa E, Albert M, Dieterich M, Haselgrove C, Van Der Kouwe A, Killiany R, Kennedy D, Klaveness S (2002) Whole brain segmentation: automated labeling of neuroanatomical structures in the human brain. Neuron 33:341-355.

Fjell AM, Westlye LT, Grydeland H, Amlien I, Espeseth T, Reinvang I, Raz N, Dale AM, Walhovd KB, Initiative ADN (2012) Accelerating cortical thinning: unique to dementia or universal in aging? Cereb Cortex 24:919-934.

Flint AJ, Gearhardt AN, Corbin WR, Brownell KD, Field AE, Rimm EB (2014) Food-addiction scale measurement in 2 cohorts of middle-aged and older women-. The American journal of clinical nutrition 99:578-586.

Fortier CB, Leritz EC, Salat DH, Venne JR, Maksimovskiy AL, Williams V, Milberg WP, McGlinchey RE (2011) Reduced cortical thickness in abstinent alcoholics and association with alcoholic behavior. Alcoholism: Clinical and Experimental Research 35:2193-2201.

García-García I, Zeighami Y, Dagher A (2017) Reward Prediction Errors in Drug Addiction and Parkinson's Disease: from Neurophysiology to Neuroimaging. Curr Neurol Neurosci Rep $17: 46$.

García-García I, Michaud A, Dadar M, Zeighami Y, Neseliler S, Collins DL, Evans AC, Dagher A (2018) Neuroanatomical differences in obesity: meta-analytic findings and their validation in an independent dataset. International Journal of Obesity.

García-García I, Horstmann A, Jurado MA, Garolera M, Chaudhry SJ, Margulies DS, Villringer A, Neumann J (2014) Reward processing in obesity, substance addiction and nonsubstance addiction. obesity reviews 15:853-869.

Gearhardt AN, Corbin WR, Brownell KD (2009) Preliminary validation of the Yale food addiction scale. Appetite 52:430-436.

Gearhardt AN, Boswell RG, White MA (2014) The association of "food addiction" with disordered eating and body mass index. Eating behaviors 15:427-433.

Gearhardt AN, Yokum S, Orr PT, Stice E, Corbin WR, Brownell KD (2011) Neural correlates of food addiction. Arch Gen Psychiatry 68:808-816.

Gerlach G, Herpertz S, Loeber S (2014) Personality traits and obesity: a systematic review. Obesity Reviews 16:32-63.

Goodman SN (1999) Toward evidence-based medical statistics. 2: The Bayes factor. Ann Intern Med 130:1005-1013.

Gustafson D, Lissner L, Bengtsson C, Björkelund C, Skoog I (2004) A 24-year follow-up of body mass index and cerebral atrophy. Neurology 63:1876.

Hassenstab JJ, Sweet LH, Del Parigi A, McCaffery JM, Haley AP, Demos KE, Cohen RA, Wing RR (2012) Cortical thickness of the cognitive control network in obesity and successful weight loss maintenance: a preliminary MRI study. Psychiatry Research: Neuroimaging 202:77-79.

Hauck C, Weiß A, Schulte EM, Meule A, Ellrott T (2017) Prevalence of 'Food Addiction' as Measured with the Yale Food Addiction Scale 2.0 in a Representative German Sample and Its Association with Sex, Age and Weight Categories. Obesity Facts 10:12-24.

Hebebrand J, Albayrak Ö, Adan R, Antel J, Dieguez C, de Jong J, Leng G, Menzies J, Mercer JG, Murphy M, van der Plasse G, Dickson SL (2014) "Eating addiction", rather than "food addiction", better captures addictive-like eating behavior. Neuroscience \& Biobehavioral Reviews 47:295-306.

Hruby A, Hu FB (2015) The epidemiology of obesity: a big picture. Pharmacoeconomics 33:673689.

Janowitz D, Wittfeld K, Terock J, Freyberger HJ, Hegenscheid K, Völzke H, Habes M, Hosten N, Friedrich N, Nauck M, Domanska G, Grabe HJ (2015) Association between waist 
circumference and gray matter volume in 2344 individuals from two adult communitybased samples. Neuroimage 122:149-157.

Janssen LK, Duif I, van Loon I, Wegman J, de Vries JHM, Cools R, Aarts E (2017) Loss of lateral prefrontal cortex control in food-directed attention and goal-directed food choice in obesity. Neuroimage 146:148-156.

Kass RE, Raftery AE (1995) Bayes Factors. Journal of the American Statistical Association 90:773-795.

Kessler RM, Hutson PH, Herman BK, Potenza MN (2016) The neurobiological basis of bingeeating disorder. Neuroscience \& Biobehavioral Reviews 63:223-238.

Kharabian Masouleh S, Arélin K, Horstmann A, Lampe L, Kipping JA, Luck T, Riedel-Heller SG, Schroeter ML, Stumvoll M, Villringer A, Witte AV (2016) Higher body mass index in older adults is associated with lower gray matter volume: implications for memory performance. Neurobiology of Aging.

Klinkman MS (1997) Competing demands in psychosocial care: a model for the identification and treatment of depressive disorders in primary care. Gen Hosp Psychiatry 19:98-111.

Körner A, Geyer M, Roth M, Drapeau M, Schmutzer G, Albani C, Schumann S, Brähler E (2008) Personality assessment with the NEO-five-factor inventory: the 30-item-short-version (NEO-FFI-30). Psychother Psychosom Med Psychol 58:238-245.

Kozak MJ, Cuthbert BN (2016) The NIMH research domain criteria initiative: background, issues, and pragmatics. Psychophysiology 53:286-297.

Lee CMY, Huxley RR, Wildman RP, Woodward M (2008) Indices of abdominal obesity are better discriminators of cardiovascular risk factors than BMI: a meta-analysis. $\mathrm{J}$ Clin Epidemiol 61:646-653.

Loeffler M et al. (2015) The LIFE-Adult-Study: objectives and design of a population-based cohort study with 10,000 deeply phenotyped adults in Germany. BMC Public Health 15:691.

Löffler A, Luck T, Then FS, Sikorski C, Kovacs P, Böttcher Y, Breitfeld J, Tönjes A, Horstmann A, Löffler M (2015a) Eating behaviour in the general population: An analysis of the factor structure of the German version of the three-factor-eating-questionnaire (TFEQ) and its association with the body mass index. PLoS One 10:e0133977.

Löffler A, Luck T, Then FS, Luppa M, Sikorski C, Kovacs P, Tönjes A, Böttcher Y, Breitfeld J, Horstmann A (2015b) Age-and gender-specific norms for the German version of the Three-Factor Eating-Questionnaire (TFEQ). Appetite 91:241-247.

Maayan L, Hoogendoorn C, Sweat V, Convit A (2011) Disinhibited Eating in Obese Adolescents Is Associated With Orbitofrontal Volume Reductions and Executive Dysfunction. Obesity 19:1382-1387.

Markus CR, Rogers PJ, Brouns F, Schepers R (2017) Eating dependence and weight gain; no human evidence for a 'sugar-addiction'model of overweight. Appetite 114:64-72.

Marqués-Iturria I, Pueyo R, Garolera M, Segura B, Junqué C, García-García I, Sender-Palacios MJ, Vernet-Vernet M, Narberhaus A, Ariza M (2013) Frontal cortical thinning and subcortical volume reductions in early adulthood obesity. Psychiatry Research: Neuroimaging 214:109-115.

Matsuo K, Nicoletti M, Nemoto K, Hatch JP, Peluso MAM, Nery FG, Soares JC (2009) A voxelbased morphometry study of frontal gray matter correlates of impulsivity. Hum Brain Mapp 30:1188-1195.

Meule A, Vögele C, Kübler A (2012) Deutsche Übersetzung und Validierung der Yale Food Addiction Scale. Diagnostica 58:115-126.

Michaud A, Vainik U, Garcia-Garcia I, Dagher A (2017) Overlapping Neural Endophenotypes in Addiction and Obesity. Front Endocrinol (Lausanne) 8:127. 
Moreno-López L, Catena A, Fernández-Serrano MJ, Delgado-Rico E, Stamatakis EA, PérezGarcía M, Verdejo-García A (2012) Trait impulsivity and prefrontal gray matter reductions in cocaine dependent individuals. Drug Alcohol Depend 125:208-214.

Opel N, Redlich R, Kaehler C, Grotegerd D, Dohm K, Heindel W, Kugel H, Thalamuthu A, Koutsouleris N, Arolt V (2017) Prefrontal gray matter volume mediates genetic risks for obesity. Molecular psychiatry.

Pardoe HR, Abbott DF, Jackson GD, Alzheimer's Disease Neuroimaging I (2013) Sample size estimates for well-powered cross-sectional cortical thickness studies. Hum Brain Mapp 34:3000-3009.

Pedram P, Wadden D, Amini P, Gulliver W, Randell E, Cahill F, Vasdev S, Goodridge A, Carter JC, Zhai G (2013) Food addiction: its prevalence and significant association with obesity in the general population. PLoS One 8:e74832.

Pennington DL, Durazzo TC, Schmidt TP, Abé C, Mon A, Meyerhoff DJ (2015) Alcohol use disorder with and without stimulant use: brain morphometry and its associations with cigarette smoking, cognition, and inhibitory control. PLoS One 10:e0122505.

Pivarunas B, Conner BT (2015) Impulsivity and emotion dysregulation as predictors of food addiction. Eating behaviors 19:9-14.

Pou KM, Massaro JM, Hoffmann U, Vasan RS, Maurovich-Horvat P, Larson MG, Keaney JF, Meigs JB, Lipinska I, Kathiresan S (2007) Visceral and subcutaneous adipose tissue volumes are cross-sectionally related to markers of inflammation and oxidative stress: the Framingham Heart Study. Circulation 116:1234-1241.

Pursey KM, Gearhardt AN, Burrows TL (2016) The relationship between "food addiction" and visceral adiposity in young females. Physiol Behav 157:9-12.

Radloff $L$ (1977) The CES-D scale a self-report depression scale for research in the general population. Appl Psychol Meas 1:385-401.

Randolph TG (1956) The descriptive features of food addiction. Addictive eating and drinking. $Q$ J Stud Alcohol 17:198-224.

Rapuano KM, Zieselman AL, Kelley WM, Sargent JD, Heatherton TF, Gilbert-Diamond D (2017) Genetic risk for obesity predicts nucleus accumbens size and responsivity to real-world food cues. Proceedings of the National Academy of Sciences 114:160-165.

Raschpichler M, Straatman K, Schroeter ML, Arelin K, Schlögl H, Fritzsch D, Mende M, Pampel A, Böttcher Y, Stumvoll M (2013) Abdominal fat distribution and its relationship to brain changes: the differential effects of age on cerebellar structure and function: a crosssectional, exploratory study. BMJ open 3:e001915.

Reber J, Feinstein JS, O'doherty JP, Liljeholm M, Adolphs R, Tranel D (2017) Selective impairment of goal-directed decision-making following lesions to the human ventromedial prefrontal cortex. Brain 140:1743-1756.

Ronan L, Alexander-Bloch AF, Wagstyl K, Farooqi S, Brayne C, Tyler LK, Fletcher PC (2016) Obesity associated with increased brain age from midlife. Neurobiology of aging 47:6370.

Schäfer A, Vaitl D, Schienle A (2010) Regional grey matter volume abnormalities in bulimia nervosa and binge-eating disorder. Neuroimage 50:639-643.

Schag K, Schönleber J, Teufel M, Zipfel S, Giel KE (2013) Food-related impulsivity in obesity and Binge Eating Disorder - a systematic review. Obesity Reviews 14:477-495.

Schulte EM, Grilo CM, Gearhardt AN (2016) Shared and unique mechanisms underlying binge eating disorder and addictive disorders. Clin Psychol Rev 44:125-139.

Schulte EM, Joyner MA, Potenza MN, Grilo CM, Gearhardt AN (2015) Current considerations regarding food addiction. Current psychiatry reports 17:19.

Schulz P, Schlotz W, Becker P (2004) Trierer Inventar zum chronischen Stress: TICS: Hogrefe.

Shahrzad Kharabian M, Frauke B, Leonie L, Markus L, Tobias L, Steffi GR-H, Matthias LS, Michael S, Arno V, Witte AV (2017) Gray matter structural networks are associated with 
cardiovascular risk factors in healthy older adults. J Cereb Blood Flow Metab 38:360372.

Skinner HH, Haines J, Austin SB, Field AE (2012) A prospective study of overeating, binge eating, and depressive symptoms among adolescent and young adult women. J Adolesc Health 50:478-483.

Smucny J, Cornier MA, Eichman LC, Thomas EA, Bechtell JL, Tregellas JR (2012) Brain structure predicts risk for obesity. Appetite 59:859-865.

Stevens L, Verdejo-García A, Goudriaan AE, Roeyers H, Dom G, Vanderplasschen W Impulsivity as a vulnerability factor for poor addiction treatment outcomes: A review of neurocognitive findings among individuals with substance use disorders. J Subst Abuse Treat 47:58-72.

Storsve AB, Fjell AM, Tamnes CK, Westlye LT, Overbye K, Aasland HW, Walhovd KB (2014) Differential longitudinal changes in cortical thickness, surface area and volume across the adult life span: regions of accelerating and decelerating change. Journal of Neuroscience 34:8488-8498.

Stunkard AJ, Messick S (1985) The three-factor eating questionnaire to measure dietary restraint, disinhibition and hunger. J Psychosom Res 29:71-83.

Su Y, Jackson T, Wei D, Quu J, Chen H (2017) Regional Gray Matter Volume Is Associated with Restrained Eating in Healthy Chinese Young Adults: Evidence from Voxel-Based Morphometry. Front Psychol 8:443.

Thompson JL, Drysdale M, Baimel C, Kaur M, MacGowan T, Pitman KA, Borgland SL (2017) Obesity-induced structural and neuronal plasticity in the lateral orbitofrontal cortex. Neuropsychopharmacology 42:1480.

Tomasi D, Volkow ND (2013) Striatocortical pathway dysfunction in addiction and obesity: differences and similarities. Crit Rev Biochem Mol Biol 48:1-19.

Vainik U, Dagher A, Dubé L, Fellows LK (2013) Neurobehavioural correlates of body mass index and eating behaviours in adults: A systematic review. Neurosci Biobehav Rev 37:279-299.

Vainik U, Neseliler S, Konstabel K, Fellows LK, Dagher A (2015) Eating traits questionnaires as a continuum of a single concept. Uncontrolled eating. Appetite 90:229-239.

Van Gaal LF, Mertens IL, Christophe E (2006) Mechanisms linking obesity with cardiovascular disease. Nature 444:875.

Vanltallie T, Yang M-U, Heymsfield SB, Funk RC, Boileau RA (1990) Height-normalized indices of the body's fat-free mass and fat mass: potentially useful indicators of nutritional status. The American journal of clinical nutrition 52:953-959.

Veit R, Kullmann S, Heni M, Machann J, Häring H-U, Fritsche A, Preissl H (2014) Reduced cortical thickness associated with visceral fat and BMI. Neurolmage: Clinical 6:307-311.

Volkow ND, Wang G-J, Fowler JS, Telang F (2008) Overlapping neuronal circuits in addiction and obesity: evidence of systems pathology. Philosophical Transactions of the Royal Society B: Biological Sciences 363:3191.

Volkow ND, Wang GJ, Tomasi D, Baler RD (2013a) Obesity and addiction: neurobiological overlaps. Obesity reviews 14:2-18.

Volkow ND, Wang G-J, Tomasi D, Baler RD (2013b) The addictive dimensionality of obesity. Biol Psychiatry 73:811-818.

Voon V, Morris LS, Irvine MA, Ruck C, Worbe Y, Derbyshire K, Rankov V, Schreiber LR, Odlaug BL, Harrison NA (2015) Risk-taking in disorders of natural and drug rewards: neural correlates and effects of probability, valence, and magnitude. Neuropsychopharmacology 40:804.

Walhovd KB, Storsve AB, Westlye LT, Drevon CA, Fjell AM (2014) Blood markers of fatty acids and vitamin $D$, cardiovascular measures, body mass index, and physical activity relate to longitudinal cortical thinning in normal aging. Neurobiology of Aging 35:1055-1064. 
Wang G-J, Volkow ND, Logan J, Pappas NR, Wong CT, Zhu W, Netusll N, Fowler JS (2001) Brain dopamine and obesity. The Lancet 357:354-357.

Willette AA, Kapogiannis D (2015) Does the brain shrink as the waist expands? Ageing Research Reviews 20:86-97.

Yokum S, Ng J, Stice E (2011) Relation of regional gray and white matter volumes to current $\mathrm{BMI}$ and future increases in BMI: a prospective MRI study. International Journal Of Obesity 36:656.

Zeeb FD, Floresco SB, Winstanley CA (2010) Contributions of the orbitofrontal cortex to impulsive choice: interactions with basal levels of impulsivity, dopamine signalling, and reward-related cues. Psychopharmacology 211:87-98.

Ziauddeen H, Farooqi IS, Fletcher PC (2012) Obesity and the brain: how convincing is the addiction model? Nature Reviews Neuroscience 13:279. 


\section{Tables:}

Table 1. Demographic characteristics and psychological measures of the sample $(n=625$, sex distribution: 344 men and 281 women).

\begin{tabular}{|c|c|c|c|c|c|}
\hline & $\mathrm{N}$ & Minimum & Maximum & Mean & $\begin{array}{c}\text { Std. } \\
\text { Deviation }\end{array}$ \\
\hline Age [years] & 625 & 20 & 59 & 40.6 & 10.8 \\
\hline $\begin{array}{l}\text { Food addiction symptom } \\
\text { score (YFAS) }\end{array}$ & 625 & 0 & 5 & 1.4 & 0.9 \\
\hline Depression scores (CES-D) & 625 & 0 & 21 & 8.4 & 4.6 \\
\hline BMI $\left[\mathrm{kg} / \mathrm{m}^{2}\right]$ & 625 & 17.7 & 55.4 & 25.7 & 4.5 \\
\hline WHR & 625 & 0.64 & 1.17 & 0.89 & 0.09 \\
\hline VAT $\left[\mathrm{mm}^{3} / \mathrm{cm}\right]$ & 444 & 0.7 & 42.4 & 10.1 & 7.5 \\
\hline SCAT $\left[\mathrm{mm}^{3} / \mathrm{cm}\right]$ & 444 & 1.36 & 88.8 & 21.6 & 12.1 \\
\hline $\begin{array}{l}\text { Cognitive restraint (TFEQ, } 0 \\
-21 \text { ) }\end{array}$ & 623 & 0 & 20 & 6.4 & 4.2 \\
\hline $\begin{array}{l}\text { Disinhibited eating (TFEQ, } 0 \\
-16)\end{array}$ & 623 & 0 & 15 & 4.4 & 2.7 \\
\hline Hunger (TFEQ, 0 - 14) & 623 & 0 & 13 & 3.6 & 2.7 \\
\hline Neuroticism (NEOFFI, 0 - 4) & 435 & 0 & 3.7 & 1.4 & 0.7 \\
\hline Extraversion (NEOFFI, 0 - 4) & 435 & 0.8 & 3.8 & 2.4 & 0.5 \\
\hline
\end{tabular}




\begin{tabular}{|l|r|r|r|r|r|}
\hline Openness (NEOFFI, 0 - 4) & 435 & 0.7 & 3.7 & 2.3 & 0.6 \\
\hline $\begin{array}{l}\text { Agreeableness (NEOFFI, 0 - } \\
4 \text { ) }\end{array}$ & 435 & 0.8 & 4.0 & 2.9 & 0.6 \\
\hline $\begin{array}{l}\text { Conscientiousness (NEOFFI, } \\
\text { - 4) }\end{array}$ & 435 & 1.5 & 4.0 & 3.1 & 0.5 \\
\hline $\begin{array}{l}\text { Screening scale of chronic } \\
\text { stress (TICS, range 0 - 48) }\end{array}$ & 423 & 0 & 37 & 13.9 & 7.1 \\
\hline
\end{tabular}

Table 2. Multiple regression analyses predicting different obesity-related measurements as a function of age, sex and YFAS symptom score

\begin{tabular}{|c|c|c|c|c|c|}
\hline & Adj. $\mathrm{R}^{2}$ & B & C.I. & $B$ & $P$ \\
\hline \multicolumn{6}{|l|}{ BMI } \\
\hline Model & 0.22 & & & & $<0.001$ \\
\hline Age & & 0.0027 & {$[0.0022,0.0032]$} & 0.41 & $<0.001$ \\
\hline Sex & & -0.03 & {$[-0.04,-0.02]$} & -0.18 & $<0.001$ \\
\hline $\begin{array}{l}\text { YFAS symptom } \\
\text { score }\end{array}$ & & 0.08 & {$[0.04,0.11]$} & 0.16 & $<0.001$ \\
\hline \multicolumn{6}{|l|}{ WHR } \\
\hline Model & 0.51 & & & & $<0.001$ \\
\hline
\end{tabular}




\begin{tabular}{|c|c|c|c|c|c|}
\hline Age & & 0.0035 & {$[0.003,0.0039]$} & 0.42 & $<0.001$ \\
\hline Sex & & -0.10 & {$[-0.11,-0.09]$} & -0.56 & $<0.001$ \\
\hline $\begin{array}{l}\text { YFAS symptom } \\
\text { score }\end{array}$ & & 0.06 & {$[0.03,0.09]$} & 0.10 & $<0.001$ \\
\hline \multicolumn{6}{|l|}{ SCAT } \\
\hline Model & 0.23 & & & & $<0.001$ \\
\hline Age & & 0.0082 & {$[0.0065,0.01]$} & 0.39 & $<0.001$ \\
\hline Sex & & 0.13 & {$[0.09,0.17]$} & 0.27 & $<0.001$ \\
\hline $\begin{array}{l}\text { YFAS symptom } \\
\text { score }\end{array}$ & & 0.22 & {$[0.10,0.35]$} & 0.15 & $<0.001$ \\
\hline \multicolumn{6}{|l|}{ VAT } \\
\hline Model & 0.54 & & & & $<0.001$ \\
\hline Age & & 0.019 & {$[0.018,0.022]$} & 0.63 & $<0.001$ \\
\hline Sex & & -0.25 & {$[-0.29,-0.21]$} & -0.36 & $<0.001$ \\
\hline $\begin{array}{l}\text { YFAS symptom } \\
\text { score }\end{array}$ & & 0.09 & {$[-0.05,0.24]$} & 0.041 & 0.19 \\
\hline
\end{tabular}


Table 3. Multiple regression analyses predicting different eating behavior and personality measurements as a function of age, sex, YFAS symptom score and BMI

\begin{tabular}{|l|l|l|l|l|l|}
\hline & Adj. $R^{2}$ & B & C.I. & $B$ & $p$ \\
\hline
\end{tabular}

Dependent variable: disinhibited eating (TFEQ)

\begin{tabular}{|l|l|l|l|l|l|}
\hline Model & 0.19 & & & $<0.001$ \\
\hline Age & & -0.068 & $\begin{array}{l}{[-0.088,} \\
0.049]\end{array}$ & -0.27 & $<\mathbf{0 . 0 0 1}$ \\
\hline Sex & & 1.16 & {$[0.77,1.56]$} & 0.22 & $<\mathbf{0 0 1}$ \\
\hline YFAS symptom & & 2.8 & {$[1.5,4.1]$} & 0.16 & $<\mathbf{0 . 0 0 1}$ \\
\hline Score & & 13.9 & {$[10.8,16.9]$} & 0.37 & $<\mathbf{0 0 1}$ \\
\hline
\end{tabular}

Dependent variable: hunger (TFEQ)

\begin{tabular}{|l|l|l|l|l|l|}
\hline Model & 0.073 & & & & $<0.001$ \\
\hline Age & & -0.051 & {$[-0.072,-0.03]$} & -0.20 & $<0.001$ \\
\hline Sex & & 0.31 & {$[-0.11,0.73]$} & 0.057 & 0.15 \\
\hline $\begin{array}{l}\text { YFAS symptom } \\
\text { score }\end{array}$ & & 3.2 & {$[1.8,4.5]$} & 0.18 & $<0.001$ \\
\hline Body Mass Index & & 5.4 & {$[2.2,8.7]$} & 0.14 & 0.0012 \\
\hline
\end{tabular}




\begin{tabular}{|c|c|c|c|c|c|}
\hline \multicolumn{6}{|c|}{ Dependent variable: Neuroticism (NEOFFI) } \\
\hline Model & 0.073 & & & & $<0.001$ \\
\hline Age & & -0.006 & $\begin{array}{l}{[-0.013} \\
0.001]\end{array}$ & -0.091 & 0.076 \\
\hline Sex & & 0.28 & {$[0.16,0.42]$} & 0.21 & $<0.001$ \\
\hline $\begin{array}{l}\text { YFAS symptom } \\
\text { score }\end{array}$ & & 0.72 & {$[0.3,1.14]$} & 0.16 & $<0.001$ \\
\hline Body Mass Index & & -0.2 & {$[-1.21,0.81]$} & -0.02 & 0.69 \\
\hline \multicolumn{6}{|c|}{ Dependent variable: Screening scale for chronic stress (TICS) } \\
\hline Model 1 & 0.035 & & & & $<0.001$ \\
\hline Age & & -0.006 & {$[-0.08,0.07]$} & -0.009 & 0.86 \\
\hline Sex & & 1.3 & {$[-0.07,2.7]$} & 0.091 & 0.061 \\
\hline $\begin{array}{l}\text { YFAS symptom } \\
\text { score }\end{array}$ & & 8.3 & {$[3.9,12.7]$} & 0.18 & 0.002 \\
\hline Body Mass Index & & -4.1 & {$[-14.7,6.6]$} & -0.041 & 0.45 \\
\hline
\end{tabular}


Table 4. Results of the cortical thickness regression analyses with YFAS symptom score (YFAS) and body mass index (BMI) for the right (rh) and left (Ih) hemisphere

\begin{tabular}{|c|c|c|c|c|c|}
\hline \multirow[t]{2}{*}{ Location } & \multirow{2}{*}{$\begin{array}{l}\text { Cluster } \\
\text { size } \\
\left(\mathrm{mm}^{2}\right)\end{array}$} & \multicolumn{3}{|c|}{ MNI coordinates } & \multirow[t]{2}{*}{$P$} \\
\hline & & $x$ & Y & Z & \\
\hline Model 1. YFAS & None & & & & \\
\hline Model 2. BMI & & & & & \\
\hline Ih lateral occipital cortex & 555.47 & -43.9 & -77.8 & -11.2 & $<0.001$ \\
\hline & 176.22 & -41.4 & -77.5 & -1.6 & 0.0012 \\
\hline Ih middle temporal cortex & 415.44 & -48.4 & -5.8 & -30.6 & $<0.001$ \\
\hline & 82.58 & -50.5 & -18.2 & -15.9 & 0.032 \\
\hline Ih superior temporal cortex & 99.23 & -49.7 & -5.9 & -18.9 & 0.02 \\
\hline rh parahippocampal cortex & 196.91 & 37.9 & -34.4 & -16.0 & $<0.001$ \\
\hline rh rostral middle frontal cortex & 331.42 & 23.7 & 57.4 & -12.5 & 0.002 \\
\hline rh lateral orbitofrontal cortex (OFC) & 428.59 & 27.3 & 18.8 & -10.5 & $<0.001$ \\
\hline rh isthmuscingulate cortex & 128.30 & 6.1 & -45.4 & 30.7 & 0.007 \\
\hline Model 3. & & & & & \\
\hline
\end{tabular}




\begin{tabular}{|l|l|l|l|l|l|}
\hline YFAS (adjusted for BMI) & none & & & & \\
\hline BMI (adjusted for YFAS) & & & & & \\
\hline Ih lateral occipital cortex & 451.3 & -43.9 & -78.1 & -11.0 & $<0.001$ \\
\hline & 95.1 & -41.4 & -77.5 & -1.6 & 0.02 \\
\hline Ih middle temporal cortex & 349.1 & -47.4 & -5.2 & -31.5 & $<0.001$ \\
\hline $\begin{array}{l}\text { Ih superior temporal cortex } \\
\text { Mh parahippocampal cortex }\end{array}$ & 70.9 & -50.7 & -18.7 & -15.7 & 0.048 \\
\hline controlling for age, sex and in Model 3 we included both YFAS symptom score and BMI \\
controlling for age and sex. & 88.26 & 37.8 & -33.4 & -16.4 & 0.02 \\
\hline rh rostral middle frontal cortex & 155.04 & 23.7 & 57.4 & -12.5 & 0.0024 \\
\hline rh insula/rh lateral OFC & 115.99 & 38.7 & 51.3 & 2.4 & 0.01 \\
\hline & 272.76 & 27.9 & 17.4 & -10.7 & $<0.001$ \\
\hline
\end{tabular}


Table 5. Results from the Bayesian model comparison between YFAS symptom score and BMI for gray matter volume/cortical thickness in predefined regions of interest. Bayes factors indicating strong evidence $(B F>20)$ are shown in bold.

\begin{tabular}{|c|c|c|c|c|c|}
\hline & Bayes factors & $\begin{array}{l}\text { YFAS vs null } \\
\text { (Model 1) }\end{array}$ & $\begin{array}{l}\text { BMI vs null } \\
\text { (Model 2) }\end{array}$ & $\begin{array}{l}\text { BMI vs YFAS } \\
\text { (Model } 2 \text { vs } \\
\text { Model 1) }\end{array}$ & $\begin{array}{llll}\text { BMI vs } & \text { BMI } & + \\
\text { YFAS } & & \\
\text { (Model } & 2 & \text { vs } \\
\text { Model 3) } & & \end{array}$ \\
\hline \multirow{5}{*}{$r$} & medial OFC & 5 & 266 & 52 & 0.86 \\
\hline & lateral OFC & 107 & 1997 & 18 & 0.09 \\
\hline & superior frontal & 0.14 & 0.59 & & \\
\hline & rostral middlefrontal & 0.28 & 2 & & \\
\hline & nucleus accumbens & 0.15 & 0.24 & & \\
\hline \multirow{5}{*}{ It } & medial OFC & 0.33 & 0.38 & & \\
\hline & lateral OFC & 0.28 & 2.57 & & \\
\hline & superior frontal & 0.11 & 0.51 & & \\
\hline & rostral middle frontal & 0.11 & 0.2 & & \\
\hline & nucleus accumbens & 48 & 1.69 & 28 & 1.6 \\
\hline
\end{tabular}




\section{Figures:}

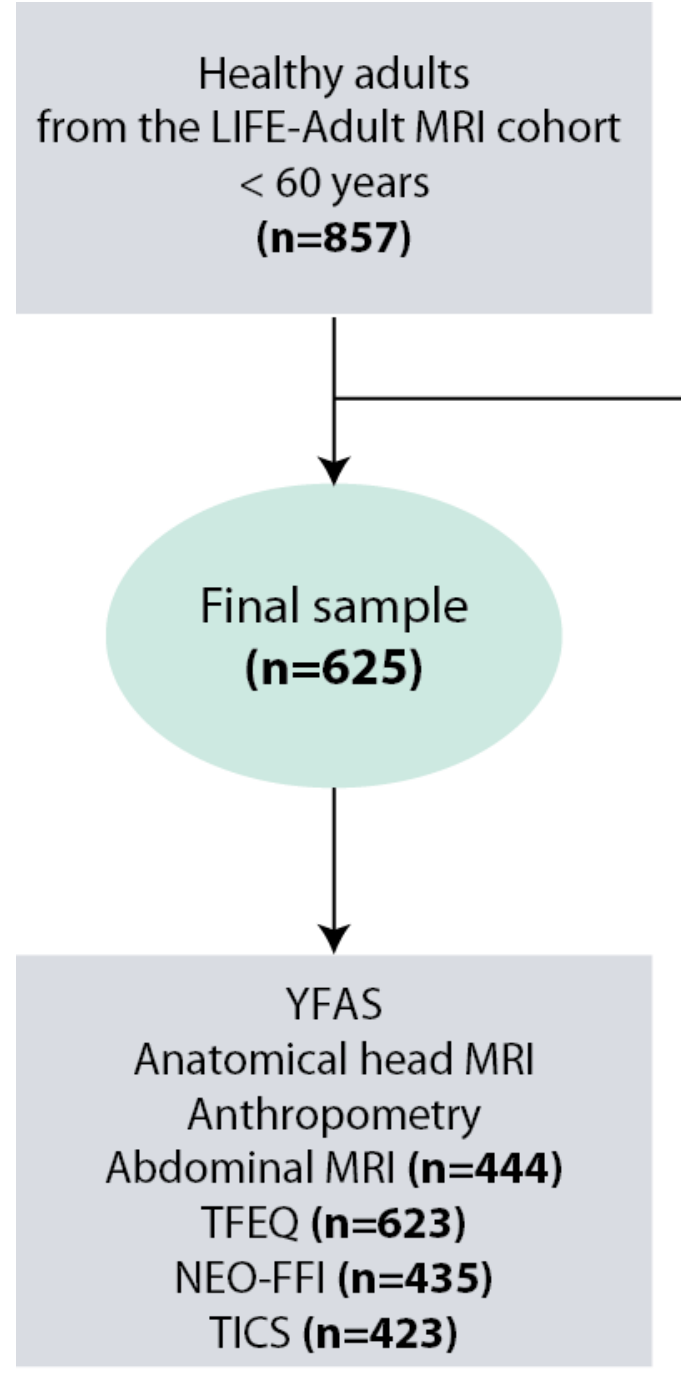

Figure 1. Flowchart showing the inclusion/exclusion criteria and variables of interest of the current study. 

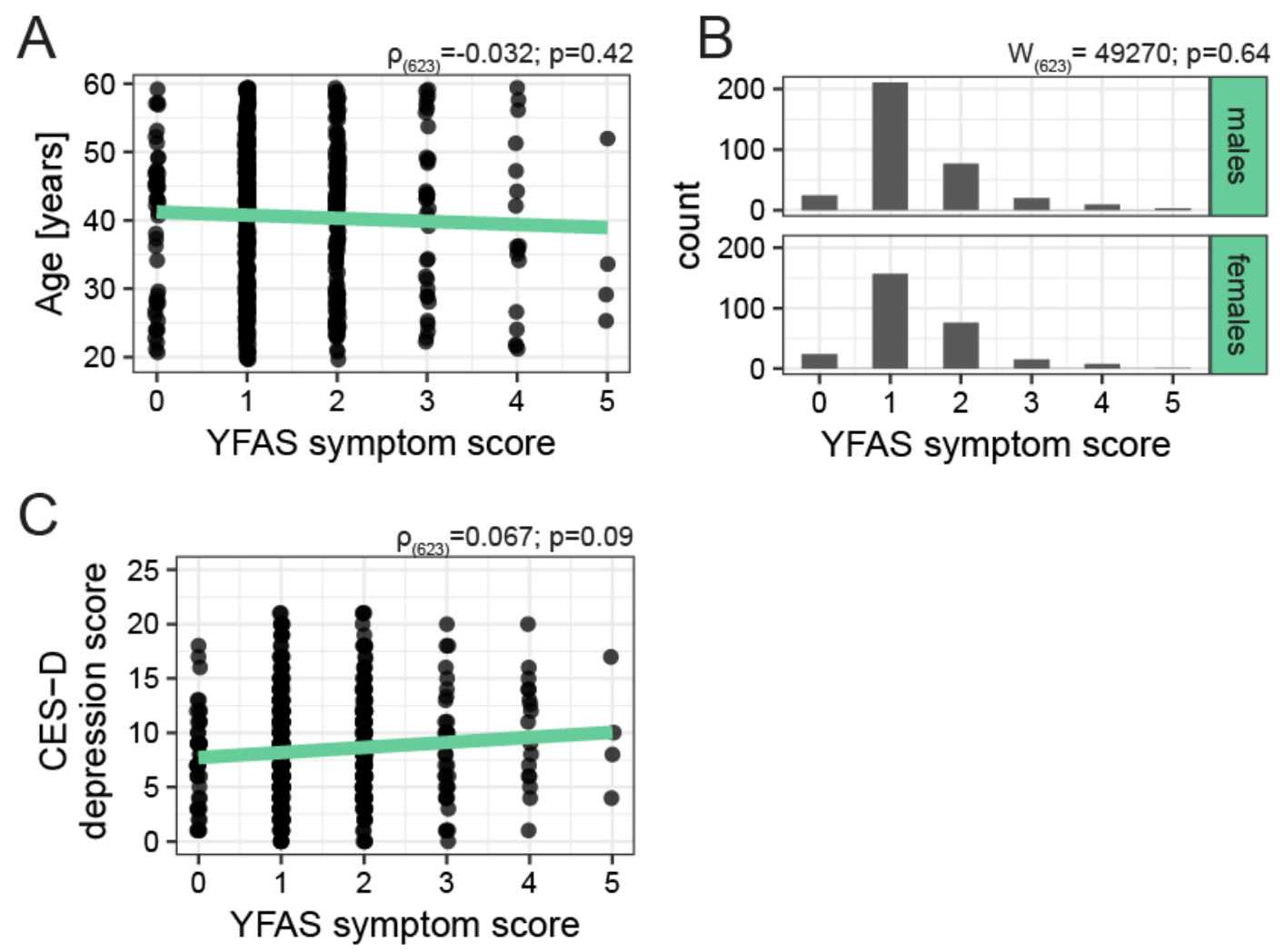

Figure 2. Relations between age (A), sex (B), CES-D depression score (C) and YFAS symptom scores in the investigated sample, visualized on the raw data. YFAS: Yale food addiction scale, CES-D: Center for Epidemiological Studies-Depression. 

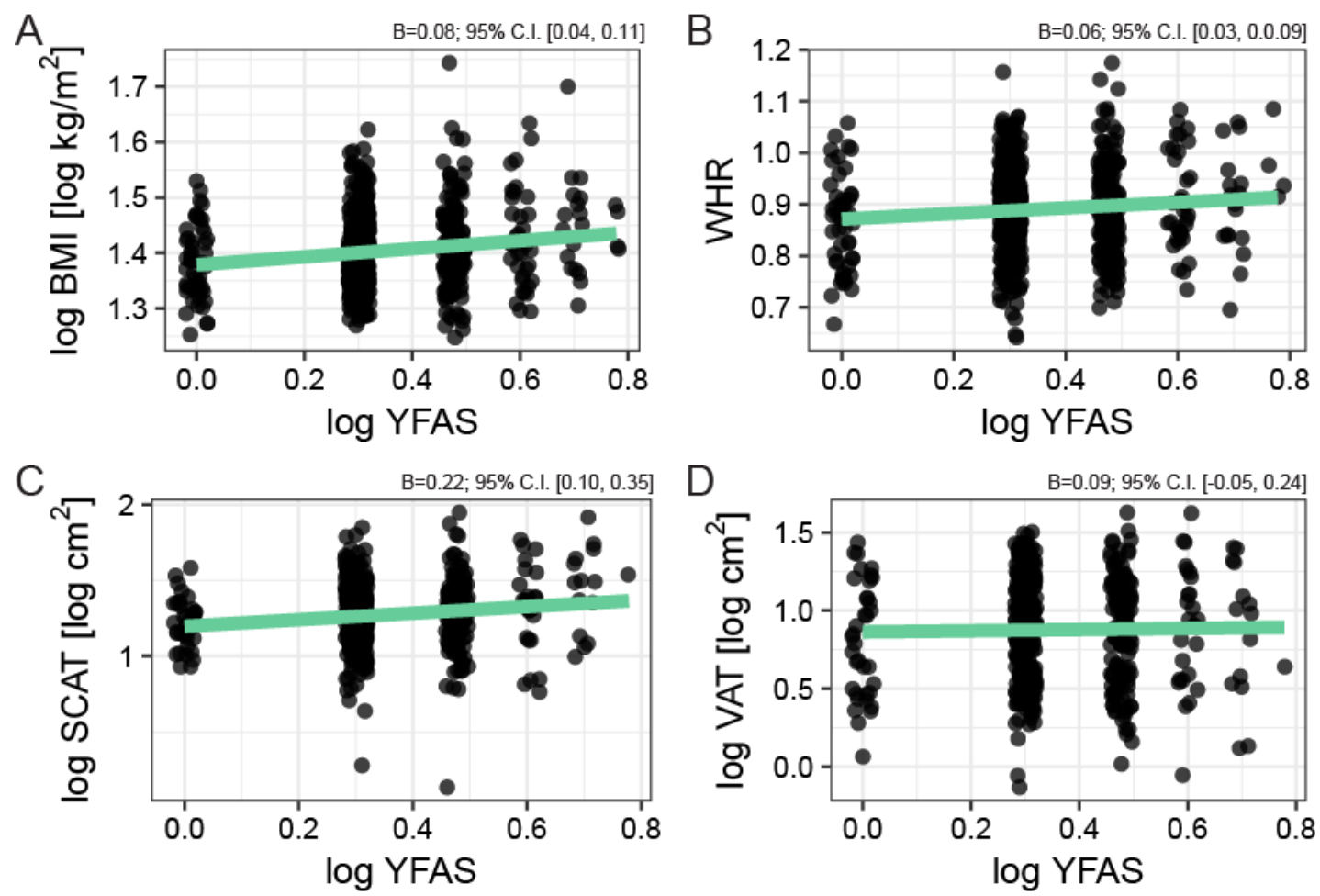

Figure 3. Associations YFAS symptom score (log-transformed) and (A) body mass index (BMI, log-transformed); (B) waist-to-hip ratio (WHR); (C) subcutanous adipose tissue (SCAT, logtransformed); and (D) visceral adipose tissue (VAT, log-transformed). The regression coefficient $B$ and confidence interval (C.I.) are based on the multiple regression analysis accounting for age and sex. 

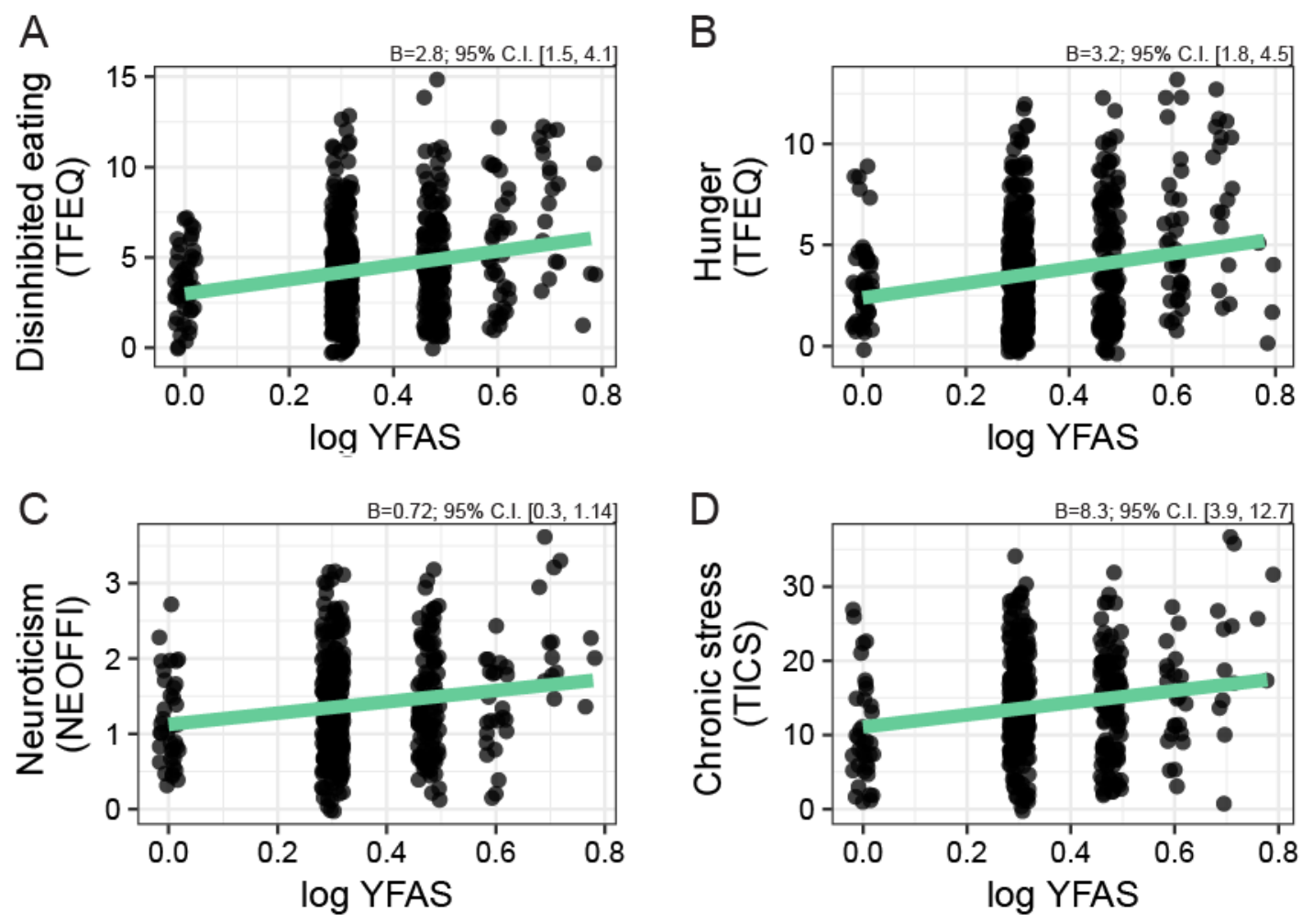

Figure 4. Significant associations between scores in YFAS symptom score (log-transformed) and (A) disinhibited eating; (B) hunger; (C) neuroticism; (D) chronic stress. The regression coefficient and confidence interval (C.I.) are based on the multiple regression analysis accounting for age, sex and BMI. 


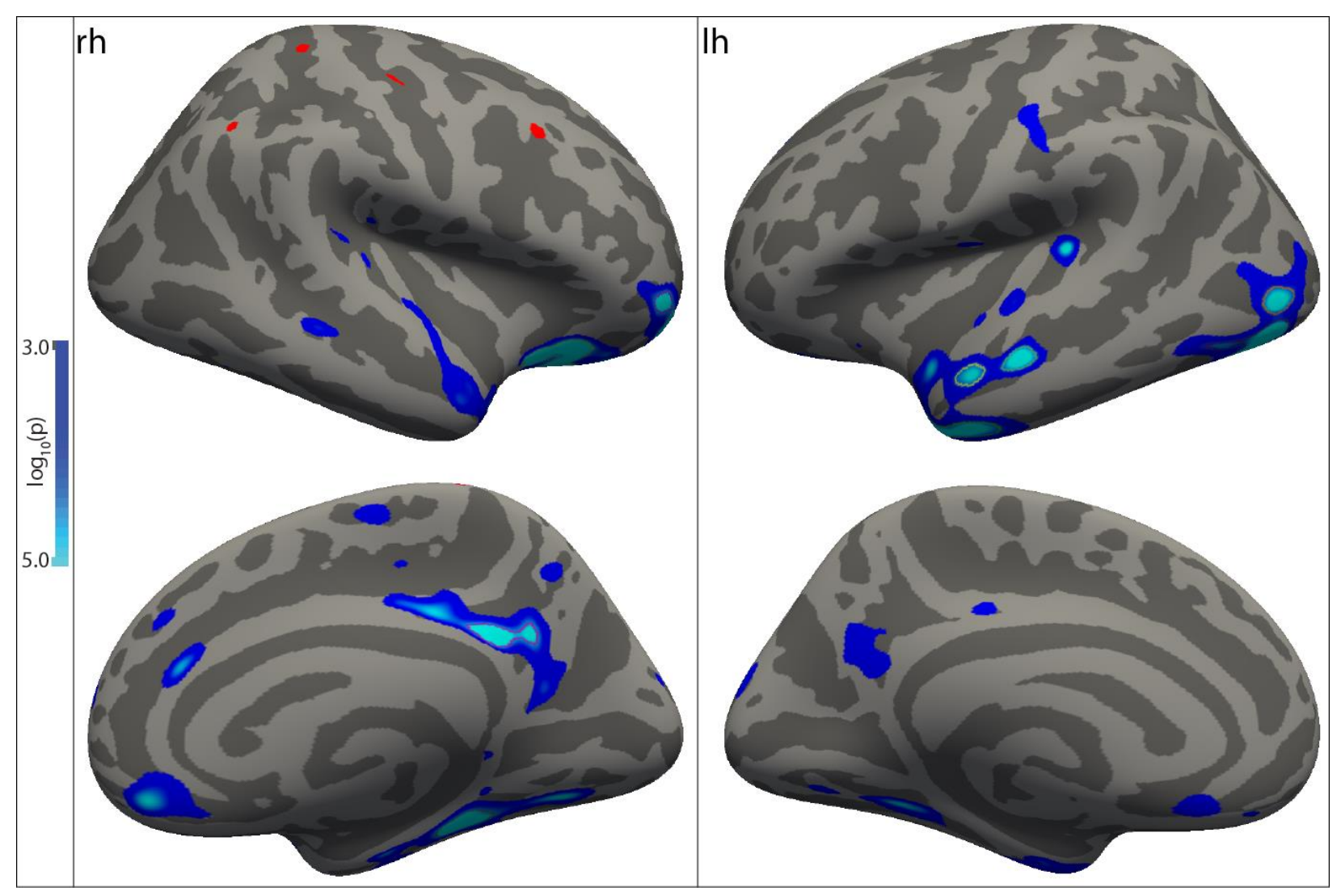

Figure 5. Higher BMI was associated with lower cortical thickness in the right lateral OFC, rostral middle frontal cortex, parahippocampal, isthmus cingulate and left lateral occipital, middle and superior temporal cortex after correcting for age and sex. The color bar represents the $\log 10(p)$ values at each vertex projected onto the Freesurfer average brain.

Appendix: 1 file with 1 figure, 1 table 